\title{
Neutron Optics Upgrades to the Residual Stress Diffractometer, KOWARI
}

\author{
Mark Reid ${ }^{1, a^{*}}$, Scott Olsen ${ }^{1, b}$, Vladimir Luzin ${ }^{1, c}$, Mark New $^{1, \mathrm{~d}}$, Norman Booth $^{1, \mathrm{e}}$, \\ Douglas Clowes ${ }^{1, \mathrm{f}}$, Tai Nguyen ${ }^{1, \mathrm{~g}}$, Ferdi Franceschini ${ }^{1, \mathrm{~h}}$, Adrian Ogrin ${ }^{1, \mathrm{j}}$, Steven \\ Pangalis $^{1, k}$, Ania Paradowska ${ }^{1, \mathrm{I}}$, Nathan Larkin ${ }^{2, \mathrm{~m}}$, Zengxi Pan ${ }^{2, \mathrm{n}}$, Nic $\mathrm{Hoye}^{2, \mathrm{o}}$ and \\ Hiroshi Suzuki ${ }^{3, p}$ \\ ${ }^{1}$ Australian Centre for Neutron Scattering, ANSTO, Lucas Heights, 2234 NSW Australia \\ 2 University of Wollongong, Wollongong 2522 NSW Australia \\ 3 Japanese Atomic Energy Agency, 300-4352 Tsukuba, Japan \\ amarkr@ansto.gov.au, bsol@ansto.gov.au, cvll@ansto.gov.au, dmln@ansto.gov.au, \\ enormanb@ansto.gov.au, ${ }^{\mathrm{f}} \mathrm{dcl} @ a n s t o . g o v . a u,{ }^{9}$ tai@ansto.gov.au hffr@ansto.gov.au, \\ jaog@ansto.gov.au, kstevenp@ansto.gov.au, 'anp@ansto.gov.au, mnlarkin@uow.edu.au, \\ nzpan@uow.edu.au, ’nhoye@uow.edu.au ${ }^{\mathrm{p}}$ suzuki-tokai@ss.em-net.ne.jp
}

\section{Keywords: Residual Stress, Robotics, Texture, Neutron Optics \& Alignment}

\begin{abstract}
In the last 5 years a number of significant enhancements have been implemented on the neutron beam strain scanner Kowari at the OPAL reactor in Sydney Australia. These changes have resulted in reduced beam time losses when conducting experiments due to sample and stage alignment, and optics and sample changes. There have been 3 projects, starting in 2011 with a new manual slit system design and collision recovery system, in 2013 with a series of radial collimators and finally with the delivery of a 6 axis robot capable of texture measurements and of running up to 20 samples automatically.
\end{abstract}

\section{Introduction}

The thermal neutron residual strain scanner, Kowari, has been operational since 2007. On the residual strain stress scanning instrument KOWARI the spatial resolution ranges from 0.2 to 1000 $\mathrm{mm}^{3}$. The resolution in lattice strain is of the order $0.01 \%$ giving a stress resolution in steels of $\sim 20$ $\mathrm{MPa}$. The instrument has been operated accordingly to ISO/TS 21432-2005 to achieve reproducible and reliable stress measurements [1,2]. Initially sample alignment and changes to the neutron optics were both slow and ergonomically challenging.

A project commenced in 2011 to design and manufacture a new neutron optics exchange system, to improve the slit system through improved collision protection and appature control and to allow much faster change over between configurations of the neutron optics (currently, three options are available: slit system, radial collimator, open detector). The new system allows for rectangular gauge volumes of quite a large size range, and has extended toolkit for accurate alignment and built-in anticollision system. After a successfully series of tests with collimators borrowed from the JRR-3M reactor a project commenced in 2013 to design and purchase a series of collimators.

Texture measurements have been undertaken for many years using a standard Euler cradle. Sample changes were thus manually made every 4-8 hours depending on sample and conditions. To increase productivity and lower exposures for users a 6 axis robotic sample changer began operating on KOWARI in 2015 which allows automated testing of 20 (in some cases more) samples.

\section{Adjustable Slit system that is collision resistant and easy to align.}

The first part of the project consisted of a rotation stage for the input and output optics system. This stage accurately and easily allowed the neutron optics (primary slits and secondary slits or 
collimators) to be swung 90 or 180 degrees and then locked into position. The second part of the project consisted of a new kinematic mount design - a ball and socket design with tangential locating pins that, in the event of a collision would allow the slits to safely rotate away. The slits can then be quickly placed back into the correct position by hand. The slits had to have a very small profile so that they could be placed as close to the sample as possible, a limitation of 4 blade slit systems. The slits are manually adjusted in a vertical range from 1 to $30 \mathrm{~mm}$, blades of different sizes allow the horizontal opening to be varied, to any desired opening up to $10 \mathrm{~mm}$. The slits package can be adjusted in 2 directions and by 2 rotations (Fig1,2).
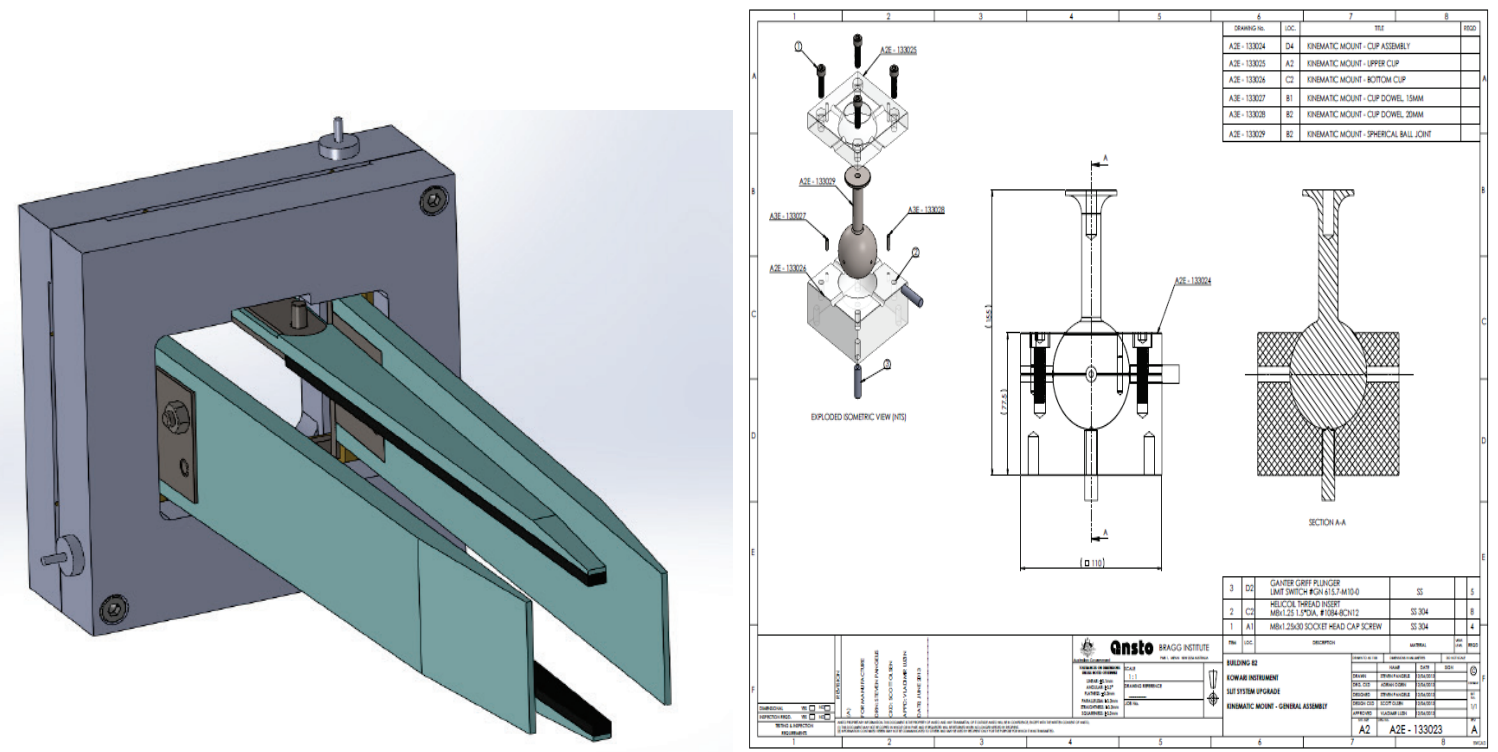

Figure 1. (Left) Solidworks model of the slit system.

Figure 2. (Right) Schematic of the ball and socket system installed to minimize damage to the slits in the event of a collision.

\section{A Series of Radial Collimators.}

A series of calculations was undertaken to (see Table 1) compare the performance of a collimator and the existing slit. The results indicated that $2 \mathrm{~mm}$ and larger sized collimators would provide a similar neutron flux and a similar strain error, as long as there was full detector coverage. The collimators have a $14^{\circ}$ degree vertical field of view and $5^{\circ}$ horizontal (except for the $10 \mathrm{~mm}$ collimator which has a $15^{\circ}$ horizontal field of view).

Tests were conducted using collimators from JRR-3M, though they were not optimised for our detector size and solid angle. The collimators were built and optical tested in Japan by Hitachi Denki Kogyo and commissioning experiments ran both in Tsukuba and Sydney. On their arrival in 2014 their performance was characterised and they were found to perform as expected. Given in table 2 is a comparison of the performance of the new radial collimators to the existing slit system. It should be noted this is the optimal performance of the slit system and in reality the slits would be expected to not to perform this well as in real experiments they would have to be positioned further from the sample. 


\section{Counting statistics characterization}

\section{QuBS Onsto}

\section{Strain error and intensity ratio}

\begin{tabular}{|c|c|c|c|c|}
\hline \multicolumn{2}{|c|}{ Size } & $0.5 \mathrm{~mm}$ & $3 \mathrm{~mm}$ & $5 \mathrm{~mm}$ \\
\hline \multirow{3}{*}{ Slit } & $\begin{array}{c}\text { Strain } \\
\text { error }\end{array}$ & $\begin{array}{c}2.1 \times 10^{-5} \\
(100 \%)\end{array}$ & $\begin{array}{c}2.2 \times 10^{-5} \\
(100 \%)\end{array}$ & $\begin{array}{c}2.2 \times 10^{-5} \\
(100 \%)\end{array}$ \\
\cline { 2 - 5 } & Int. ratio & $100 \%$ & $100 \%$ & $100 \%$ \\
\hline \multirow{3}{*}{ RC* } & $\begin{array}{c}\text { Strain } \\
\text { error }\end{array}$ & $\begin{array}{c}4.3 \times 10^{-5} \\
(205 \%)\end{array}$ & $\begin{array}{c}3.0 \times 10^{-5} \\
(136 \%)\end{array}$ & $\begin{array}{c}3.1 \times 10^{-5} \\
(141 \%)\end{array}$ \\
\cline { 2 - 5 } & Int. ratio & $31 \%$ & $60 \%$ & $64 \%$ \\
\hline \multirow{4}{*}{ RC** } & $\begin{array}{c}\text { Strain } \\
\text { error }\end{array}$ & $\begin{array}{c}3.0 \times 10^{-5} \\
(143 \%)\end{array}$ & $\begin{array}{c}2.1 \times 10^{-5} \\
(93 \%)\end{array}$ & $\begin{array}{c}2.2 \times 10^{-5} \\
(100 \%)\end{array}$ \\
\cline { 2 - 5 } & Int. ratio & $62 \%$ & $110 \%$ & $118 \%$ \\
\hline
\end{tabular}

* As-measured ( $50 \%$ detector coverage)

** Assumption of $100 \%$ detector coverage

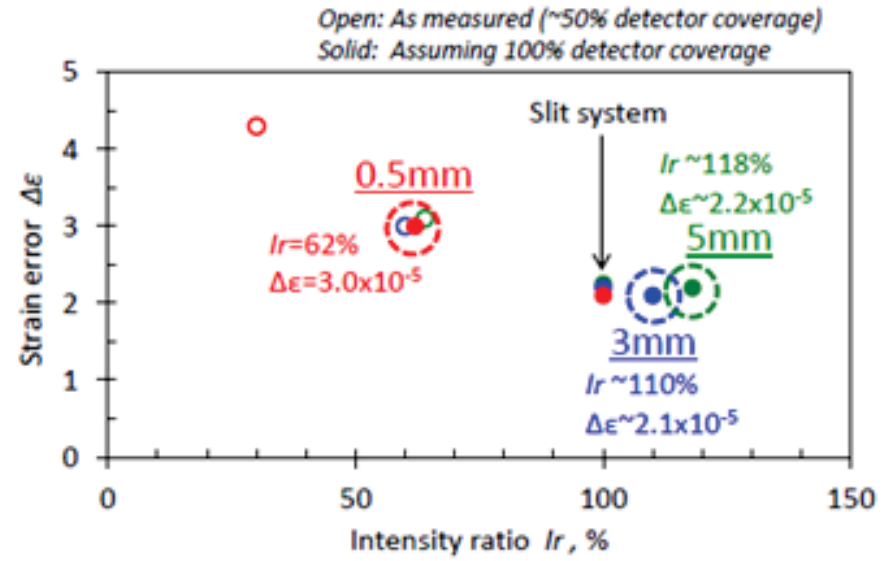

Table 1 (left) - Theoretical comparison of Collimator vs Slit performance for 0.5mm, 3 and $5 \mathrm{~mm}$.

Figure 3 (right) - Graphical comparison of the Intensity vs strain error

\begin{tabular}{|c|c|c|c|c|}
\hline \multicolumn{2}{|c|}{ Size } & $2 \mathrm{~mm}$ & $3 \mathrm{~mm}$ & $5 \mathrm{~mm}$ \\
\hline \multirow{8}{*}{ Slit } & $\begin{array}{c}\text { Strain } \\
\text { error }\end{array}$ & $\begin{array}{c}4.33 \times 10 \\
-5 \\
(100 \%)\end{array}$ & $\begin{array}{c}4.66 \times 10 \\
-5 \\
(100 \%)\end{array}$ & $\begin{array}{c}4.93 \times 10 \\
-5 \\
(100 \%)\end{array}$ \\
\cline { 2 - 5 } & $\begin{array}{c}\text { Int. } \\
\text { ratio }\end{array}$ & $100 \%$ & $100 \%$ & $100 \%$ \\
\hline \multirow{3}{*}{ RC } & $\begin{array}{c}\text { Strain } \\
\text { error }\end{array}$ & $\begin{array}{c}5.56 \times 10 \\
-5 \\
(129 \%)\end{array}$ & $\begin{array}{c}4.98 \times 10 \\
-5 \\
(107 \%)\end{array}$ & $\begin{array}{c}4.70 \times 10 \\
-5\end{array}$ \\
\cline { 2 - 5 } & $\begin{array}{c}\text { Int. } \\
\text { ratio }\end{array}$ & $80 \%$ & $84 \%$ & $103 \%$ \\
\hline
\end{tabular}

This highlights one of the major benefits of the RC's, they are positioned $500 \mathrm{~mm}$ away from the measurement position allowing easy positioning of large samples. Additionally as shown in Fig. $4 a \& b$, they were found to be insensitive to rotational orientation in both intensity and peak FWHM, making alignment trouble free. Since their introduction they have been heavily utilised.

Table 2 Comparison of the strain error and intensity ratio of the existing slit system and the new radial collimators. 


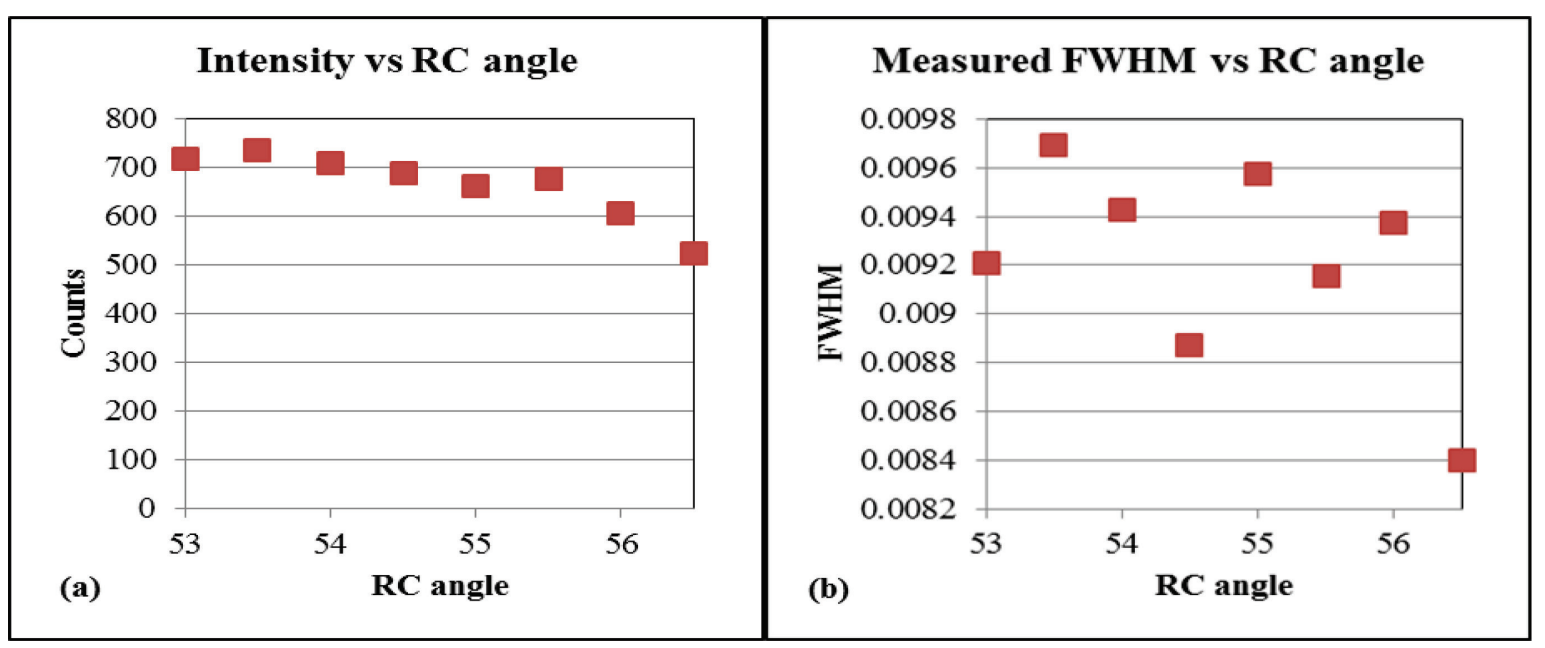

Figure 4 Intensity (a) and FWHM (b) of the measured peak vs. rotational (nominal) angle of the $2 \mathrm{~mm}$ radial collimator.

\section{A 6 axis robot for higher throughput and texture measurements.}

Texture analysis on KOWARI has been undertaken using standard Eulerian cradles since 2007. Generally 3-5 sample changes were undertaken per day. Depending on the activation of the sample and the method of alignment between 10 and 30 minutes was lost per sample change. A 100 sample position 4 axis robot, an Epson E2S5553 had been used on the powder diffractometers at ANSTO since 2009 [3]. In 2011 it was decided that a 6 axis robot, capable of texture analysis would be purchased. At that time few if any facilities had this capability, we are currently aware of 2 facilities that can now do this, STRESS-SPEC at FRM II in Munich [4] and at the LANCSE facility in Los Alamos [5].

An Epson C3 6 axis robot was selected. The specifications are shown in Table 3. Software design commence at the University of Wollongong and an analysis of the robot's accuracy and repeatability with undertaken. The design requirement was $<0.2 \mathrm{~mm}$, ideally $0.1 \mathrm{~mm}$. Tables 4 and 5 over show the results. A rotation in Chi is much simpler as it is a single joint movement only.
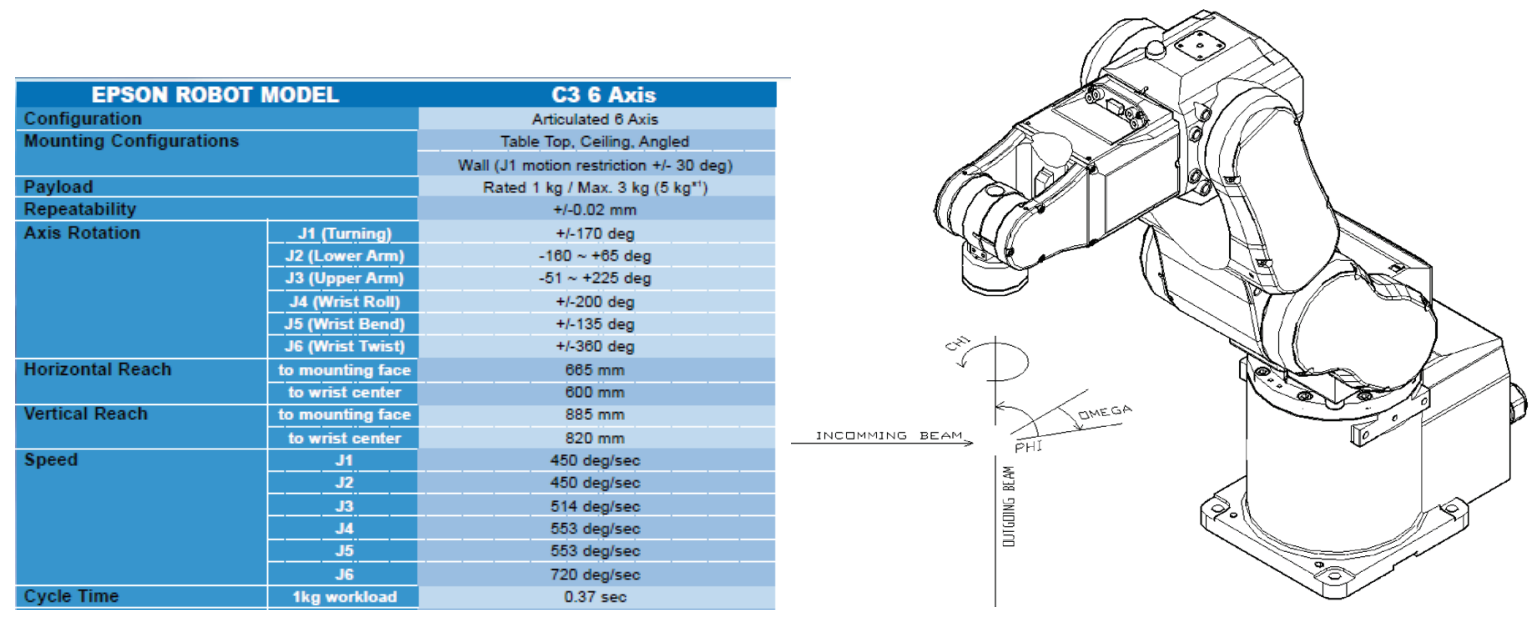

Table 3 (left) specifications for the 6 axis robot selected for texture analysis

Figure 4 - Schematic of the robot showing the principles degrees of rotation 


\begin{tabular}{c|ccc}
\hline Angle $($ Chi) & Error to Plane $(\mu \mathrm{m})$ & Error to Circle $(\mu \mathrm{m})$ & Total Error $(\mu \mathrm{m})$ \\
\hline 0 & 15 & 27 & 31 \\
10 & 6 & -38 & 38 \\
20 & 10 & 11 & 15 \\
30 & 8 & 3 & 9 \\
40 & 6 & -21 & 22 \\
50 & 2 & 1 & 2 \\
60 & 11 & 2 & 12 \\
70 & 29 & 26 & 39 \\
80 & 12 & 18 & 22 \\
90 & 11 & -29 & 31 \\
\hline
\end{tabular}

Table 4 - Test with Omega at 0 degrees, of rotations in Chi.

\begin{tabular}{c|ccc}
\hline Angle $($ Phi) & Error to Plane $(\mu \mathrm{m})$ & Error to Circle $(\mu \mathrm{m})$ & Total Error $(\mu \mathrm{m})$ \\
\hline 0 & 101 & -5 & 101 \\
10 & 36 & 4 & 36 \\
20 & 82 & 12 & 83 \\
30 & 65 & -22 & 69 \\
40 & 53 & 21 & 57 \\
50 & 35 & -6 & 36 \\
60 & 97 & 0 & 97 \\
70 & 105 & -16 & 106 \\
80 & 14 & 16 & 21 \\
90 & 116 & -3 & 116 \\
\hline
\end{tabular}

Table 5 - Test with Omega at 30 degrees of rotations in Phi, a more complex operation..

After some final in house software modifications and a new 20 position sample changer were fabricated the first texture analysis experiments were undertaken on KOWARI and on the high intensity powder diffractometer WOMBAT in 2015. Comparisons with samples run on conventional Euler cradles have been undertaken (see Figures 7,8) - they show very close agreement. Aside from metallurgical samples geological samples and cultural heritage samples have been recently batch tested $[6,7,8]$.

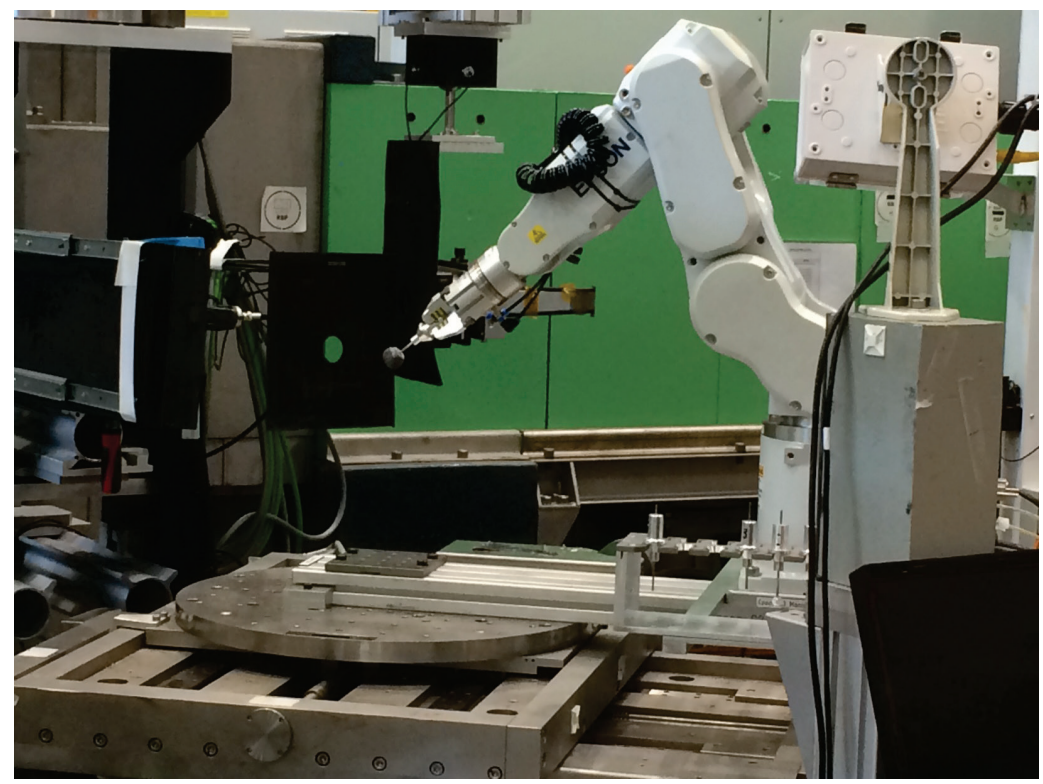

Figure 6. The 6 axis robot on KOWARI with the 20 position sample changer in the lower right. 

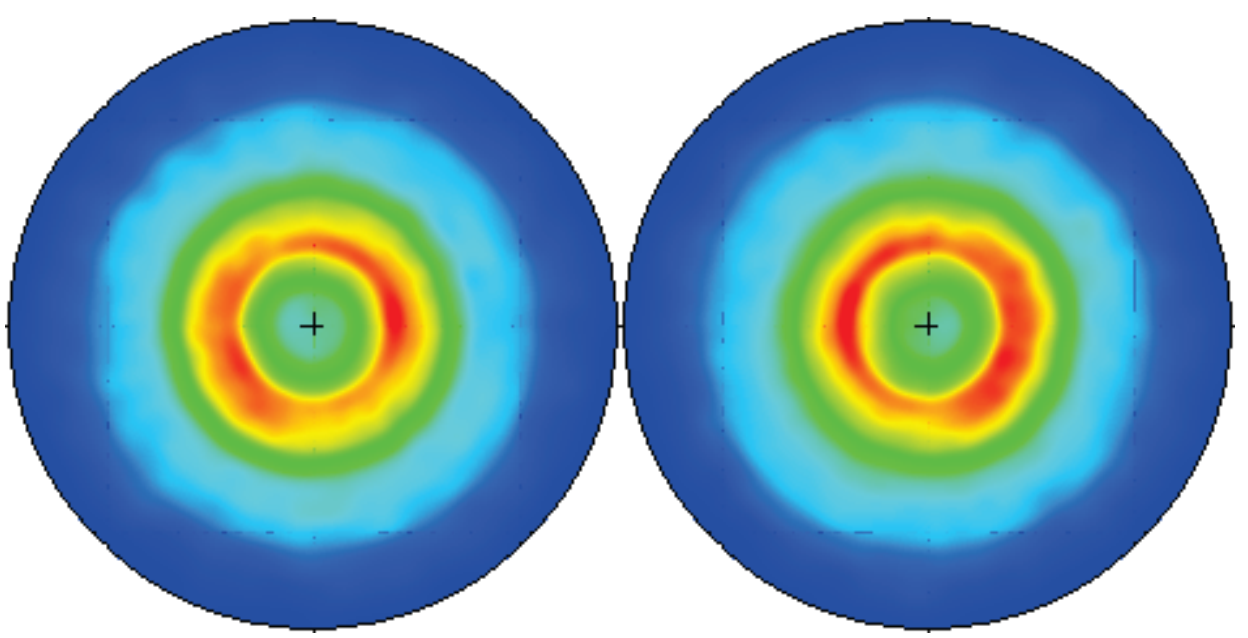

Figure 7 (Left) Pole figure Ag(1,1,1) Sample measured with the robot.

Figure 8 (Right) Pole figure Ag(1,1,1) Sample measured with the Eulerian Cradle.

\section{Summary}

Significant upgrades to the Neutron Residual Stress Scanner KOWARI at ANSTO have been undertaken in the last 5 years. There has been a significant reduction in beam time lost due to alignment and sample changing.

\section{References}

[1] A.Brule \& O.Kirsten, Residual stress diffractometer KOWARI at the Australian Research Reactor OPAL: Status of the project 2006 Physics B 385-386, 1040-1042 (2006) 45

[2] O. Kirstein, V. Luzin \& U. Garbe, The Strain-Scanning Diffractometer Kowari, Neutron News Vol. 2009 20(4)

[3] S.R.Olsen, S.A.Pullen, M.Avdeev, A 100 position robotic sample changer for powder diffraction with low background vacuum chamber, Journal of Applied Crystallography 43:2 (2010) 377-379. http://dx.doi.org/10.1107/S0021889810003614

[4] C.H.Randau, H. G. Brokmeier, W. M. Gan, M. Hofmann, M. Voeller, W. Tekouo, N. Alhamdany, G. Seidl, and A. Schreyer. "Improved sample manipulation at the STRESS-SPEC neutron diffractometer using an industrial 6-axis robot for texture and strain analyses." Nuclear Instruments and Methods in Physics Research Section A: 794 (2015): 67-75.

http://dx.doi.org/10.1016/j.nima.2015.05.014

[5] A.S.Losko, S. C. Vogel, H.M.Reiche, and H.Nakotte. A six-axis robotic sample changer for highthroughput neutron powder diffraction and texture measurements. Journal of Applied Crystallography 47, no. 6 (2014): 2109-2112. http://dx.doi.org/10.1107/S1600576714021797

[6] K.A. Sheedy, P. Munroe, F. FSalvemini, V. Luzin, U. Garbe and S.R Olsen, An incuse stater from the series 'Sirinos/Pyxoes', Journal of the Numismatic Association of Australia 26 (2015), 3652.

[7] F.F.Salvemini, S.R.Olsen, V.Luzin, U.Garbe, J.Davis, T.Knowles, K.A.Sheedy, Neutron tomographic analysis: Material characterization of silver and electrum coins from the 6th and 5th centuries BCE, Mater. Charact. 118, 175-185 (2016). http://dx.doi.org/10.1016/j.matchar.2016.05.018

[8] S.R.Olsen, E.P.Gilbert, N.Booth, S.A. Pullen, P.Imperia, V.K. Peterson, U.Garbe et al. "Novel non-destructive sample analysis techniques using neutron scattering." 8th Australasian Congress on Applied Mechanics (2014): 723-730. 